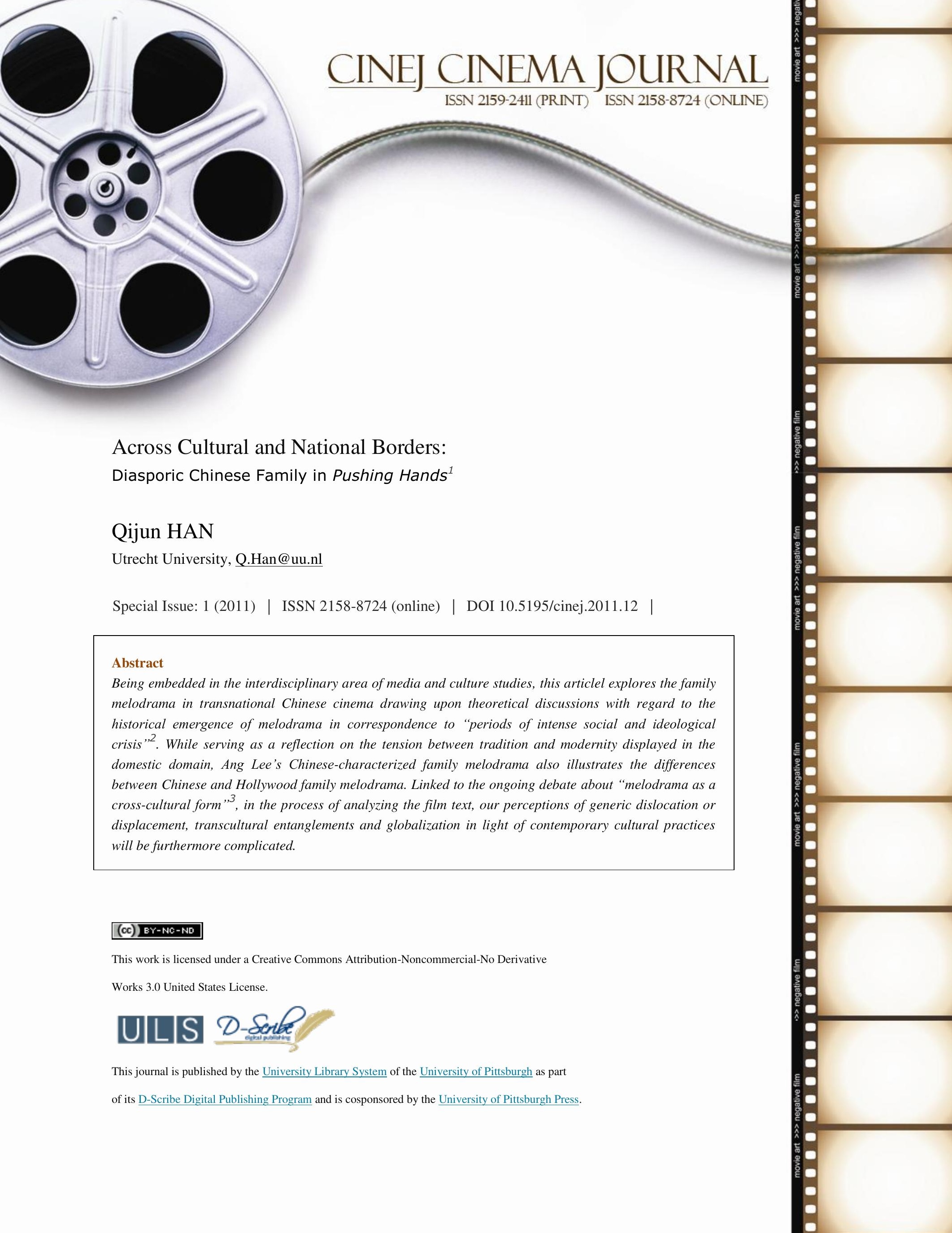




\title{
Across Cultures and National Borders: Diasporic Chinese Family in Pushing Hands
}

\begin{abstract}
"A family is like your own personal anti-matter. Your family is the void you emerge from and the place you return to when you die and that's the paradox - the closer you're drawn back in, the deeper into the void you go."
\end{abstract}

- Paul Hood, Ice Storm (Ang Lee, 1997)

\section{Introduction}

As one of Ang Lee's favorite themes, family has been present in most of his works. In an overview of his oeuvre, starting from Pushing Hands (1992) - his first feature film, to his more recent film Taking Woodstock (2009), from Sense and Sensibility (1995), to The Ice Storm (1997), Lee has proven himself to be the master of bittersweet family melodramas to capture the melodramatic conflicts in both Chinese and non-Chinese families. Including Ang Lee, numerous Chinese and diasporic Chinese filmmakers have utilized the cinematic form of family melodrama to reflect the complexity of family domain, where different types of conflicts among gender, cultures, generations, class, and nations, are more often than not displayed. The family thus can be seen as a representation of a cultural crisis. However, the link between melodrama as a concept largely developed in Europe and North America, and its function in transnational Chinese cinema ${ }^{4}$, is rarely touched upon. This paper, therefore, will initiate an attempt to embark on an exploration of the complexity of melodrama as well as family melodrama in the Chinese context.

The essay will be divided into two interrelated parts. In the first part, I shall engage in discussion on the concept of melodrama and family melodrama and how it can aid us in understanding a typical Chinese familymelodrama film. In the second part, I will analyze the film text within the frame of the first part. In so doing, the discourse of family melodrama will be problematized and complicated by nationally-, ethnically- and culturallyspecific Chinese family melodrama.

\section{Revisiting Melodrama}

Before investigating the concept of family melodrama, we shall first start with clarifying the meaning of melodrama, since there have been abundant research that addresses melodrama's ideological complexity. In a strict sense, "melodrama" originally refers to dramas combined with music. As a popular and hybrid cultural form, melodrama often seeks to address the widest possible audience. Containing "elements of interiorization and personalization of what are primarily ideological conflicts", 5 much of the melodramatic conflicts center on generation and gender relationships. Melodrama thus is often linked to woman's film and family melodrama.

A great deal of discussions has been devoted to revitalize melodrama as a fixed genre, despite the fact that melodrama is rather fluid and unfixed and that it is also transnational and transcultural. I however, share more in line with Linda Williams that melodrama can be seen as a mode encompassing many different genres. 
Melodrama is the fundamental mode of popular American moving pictures. It is not a specific genre like the western or horror film; it is not a 'deviation' of the classical realist narrative; it cannot be located primarily in woman's films, 'weepies', or family melodramas - though it includes them. Rather, melodrama is a peculiarly democratic and American form that seeks dramatic revelation or moral and emotional truths though a dialectic of pathos and action."

As a dramatic and literary form, melodrama was already very popular as early as in the late 18th century. Because of its function as a site of ideological struggle, silent movies drew on theatrical melodrama and developed a form of cinematic melodrama. By mediating the spiritual realm of freedom and the empirical realm of bondage, melodrama has manifested its ability of allowing film directors to tackle 'taboo' issues, desires and demands barred by thresholds raised in social and political code. However, melodrama has long been despised by film historian and critics, both in China and in the West.

Being recognizably emotional and sentimental, melodrama is often reduced to low-brow form and is discarded for its main association with woman and low class. Melodrama, a "mode of excess", 7 was dismissed as trivial for requiring no skill at all. But this is far from the truth, for respectable masters of melodrama such as Griffith, Vidor, Minnelli, Sirk, have been looked upon by many close followers. In the early 1970s, melodrama finally became recognized as well as promoted by film scholars such as Peter Brooks, Thomas Elsaesser, and Geoffrey Nowell-Smith. The term entailed quite another meaning during and after the 1970s than before, though, since the debates on melodrama have taken points of view largely from Marxism, psychoanalysis, feminism.

With the popularity of television melodrama, especially Korean soap operas in China in the past decade, melodrama's "myth-making function" 8 has attracted attention from some media scholars. They have studied its ability of revealing social aspirations as well as gender and class paradoxes, yet the lack of research in Chineselanguage melodrama films is still striking. The danger of engaging in such a study lies in the difficulty of applying a western discourse in the Chinese context. Linked to the rejection of melodrama in China is the association of melodrama with political decolonization and de-westernization, an on-going process that went through the second half of the $20^{\text {th }}$ century and continues in the $21^{\text {st }}$ century.

Inspired by Edward Said (1978), Michel Foucault (1980), Fredric Jameson (1986) and other postcolonial scholars such as Homi Bhabha (1983) and Gayatri Spivak (1988, 1990), cross-cultural reading politics has arisen as a hot debate in film studies in the late 1980s. Central to the concerns is who is doing cultural analysis and for what purpose. In light of these thoughts, Chinese comparative literartist Zhang Longxi (1992) has reminded us to be aware of the different national and local conditions on applying Western framework. Following similar lines, many Chinese film critics propose to abandon generic division, and replace it with the concept of mode, since generic categorization in film studies is mostly developed in Europe and North America. To address the specificity of Chinese cinema, melodrama has been substituted with following modes: Zheng Zhengqiu mode (family melodrama), Cai Chusheng mode (social melodrama) and Xie Jin mode (political melodrama). ${ }^{9}$ Film scholars, such as Professor Emilie Yueh-yu Yeh, and Cai Guorong, the scriptwriter for Crouching Tiger, hidden Dragon, have suggested us to replace the term melodrama with wenyipian (文艺片) or literature-art-films, ${ }^{10}$ which seemingly more specific to Chinese cinema's critical and production contexts.

While I share their concern that the concept of western melodrama may not be sufficient enough to explain Chinese-language cinemas, and to a certain extent it can bring theoretical baggage, I argue that the hybrid 
nature of melodrama as a particular form allow us to depart from categorization and to see the cultural dynamic from a global perspective. Even if it is tempting and convenient to draw a neat and binary division between East and West, it, as we will see, fails to account for some exceptional cases, for instance, Hong Kong cinema, a cultural sphere where the East mingles with the West. The same goes for the Diaspora Chinese cinema, as the overseas Chinese are still influenced by their Chinese cultural heritage, not to mention that the film production and reception in an increasingly globalized and transnational world are becoming much more complex than they used to be. By using a transnational label such as melodrama, the specificity of Chinese culture and history can be incorporated in the process of globalization and Chinese-characterized films become accessible for the global audiences. Among many other cases, Zhang Yimou and Chen Kaige, arguably the most recognized Chinese filmmakers, have used melodrama to market some of their works to the west, including Red Sorghum (Zhang, 1987), To Live (Zhang, 1990), Raise the Red Lantern (Zhang, 1991), Farewell My Concubine (Chen, 1993), to name just a few.

In the context of Chinese film production, family melodrama plays a central role. After all, as Ma Ning concludes, "The family, rather than the individual or the state, was the most significant social unit in traditional China." ${ }^{11}$ The emergence of cinema and modern melodramatic techniques and formulas in China, as part of China's modernization process, is an import from the West via Japan.

We may ask then: what exactly is family melodrama? Family melodrama is identified as a subgenre that exposes the tensions and contradictions in the post-war suburban American life, drawing inspirations mainly from Sirk's films made in the 1940s and 1950s. For Elsaesser, family melodrama, as a particular genre, "more often records the failure of the protagonist to act in a way that could shape the events and influence the emotional environment, let alone change the stifling social milieu. The world is closed, and the characters are acted upon. Melodrama confers on them a negative identity through suffering, and the progressive self-immolation and disillusionment generally end in resignation: they emerge lesser human beings for having become wise and acquiescent in the ways of the world." 12

\section{Pushing Hands - A Transnational Family Melodrama}

Then, how does Ang Lee tailor ideological conflicts into family situation in Pushing Hands by using the form of family melodrama? And in what ways does Lee's family melodrama serve to illustrate the Chinese characterized family melodrama - a simple juxtaposition of similarities and differences between Chinese and western family melodrama becomes clear in film itself?

The plot of the film mainly revolves around exploring the conflicts between generations and culture. In response to "Destroy the Four Olds" (old ideas, old culture, old customs, and old habits) campaign throughout the Cultural Revolution, considered as embodiment of superstition and old-fashioned religion, Taiji was once banned in China. As a consequence, $\mathrm{Mr} \mathrm{Chu}$ - the father, a taiji teacher, was forced to send his son to the United States for protections. Many years later, the family is reunited in America - the father, his son Alex, his American daughterin-law Martha, and his grandson Jeremy. Since the family is unprepared for the unexpected, the drama has started at the moment of the father's arrival.

As I have already pointed out before, while clearly influenced by western melodrama, Chinese family melodrama follows its own trajectory. Elsasser observes that the family melodrama is "where Freud left his Marx 
on the family home". ${ }^{13}$ E. Ann Kaplan also establishes a strong link between family romance and family melodrama. What partly defines melodrama as a form is "its concern explicitly with Oedipal issues - illicit love relationships, mother-child relationships, husband-wife relationships, father-son relationships". She also notes that Oedipal trajectories can be clearly traced in family melodrama. ${ }^{14}$

Lee's representational family, however, is certainly different from the bourgeois nuclear family that is usually present in the melodramatic plot of Hollywood films - as much about the extended family depicted in the film, as it is about an unconventional type of non-Oedipal conflict. Although Ang Lee had his educational training in the United States, his films carry strong Chinese elements. Pushing Hands is a Chinese family melodrama, but the family in the film is more than a typical Chinese family, since it has been displaced abroad. Pushing Hands thus serves as a reflection on the cultural displacements of Chinese/Chinese American family relations.

Chris Berry concludes a particular type of Taiwanese family melodrama - characterized by healthy realism, which reshapes a Confucian tradition into a hybrid Confucian ethic and a spirit of capitalism. ${ }^{15}$ Although his conclusion is drawn from his observation on Taiwanese family melodrama, a melancholy towards vanishing tradition, or moral and ethical dilemmas that are raised in era of changes, has been quite often expressed in nonTaiwanese family melodrama, such as Ann Hui's Summer Snow (also known as Woman, Forty, 1995) in which a story about a middle-aged woman trying to cope with the upheavals in her family when encountered by obstacles is told.

I will, therefore, argue that, while the western family in film studies has often been closely linked to the psychoanalytical concept of the oedipal family, the cinematic Chinese family, on the other hand, excessively plays with Confucian family ethics. Although the tendency towards nostalgia and melancholy can be clearly traced in abundance of film works, many filmmakers, rather than being trapped in conventional thinking, in fact invite the audiences to reflect upon the changes by means of displaying conflicts without taking up a particular moral stance.

Melodrama often embodies morality polarized by the notions of good and evil, which elicits excessive emotion from the viewers, but it is not the case for Pushing Hands, the movie under discussion. The absence of moral polarization in Hollywood films has been explicitly explained by Ben Singer. In Melodrama and Modernity, he points out the evolution of melodrama that eschews conventional melodramatic devices developed at the theatre.

Hollywood melodramas of the studio-system era generally involved just two of the basic elements: pathos and emotional intensification. In fact, many Hollywood melodrama hinged on the absence of the element most accentuated in classic stage melodrama - i.e., moral polarization between good and evil. Hollywood melodramas focused not on the battle between good and evil characters, but rather on the pathos of situations of moral antinomy in which two or more morally good characters find that their interests are fundamentally incompatible. ${ }^{16}$

Pushing Hands sets nexus between father and daughter-in-law as the dramatic pivot of this particular melodrama. The clash between Mr Chu and Martha - respectively representing the traditional Chinese patriarch and modern virtue of individualism, by no means defines Martha - the modern American woman writer who feels intruded upon by her father-in-law's visit - a villain. Neither is Lee's intention to judge Martha's behaviour according to Confucian moral philosophy that requires duty, obligation, respect, devotion and self-sacrifice to 
parents. The film thus can be read as a departure from many other similar films containing intercultural communication theme, in a sense that it does not prove America-centric or China-centric.

Chinese family relation is characterized by the well-known filial piety. In Chinese culture where the extended family is still valued, less than before, though, it is commonly to see three generations - father, son, and grandson, living under the same roof. In extended families, the daughter-in-law is in general regarded as a workhorse in her household and she is restricted to the role of taking care of her parents-in-law, husband, as well her children. However, in an intercultural context, family is no longer subject to its traditional definition. Rather, families become the subject of their making. The meaning of family is thus attached by interpersonal relations. In this way, a domestic melodrama like Pushing Hands has very effectively demonstrated how interpersonal relations/conflicts within the family can redefine family.

Certainly the film is packed with all sorts of conflicts. Lee, together with his ever-present camera, captures several melodramatic scenes, in which the characters externalize their internal conflict. A central concern in Pushing Hands is the ideological implication - to which extent this particular Chinese family melodrama has inscribed the representation of family conflict and the resolution. I will thus approach the film text from two perspectives - representation of melodramatic conflict displayed in the domestic sphere as well as a possible conflict resolution. As such, the traits of Chinese family melodrama will be highlighted.

Given the important role that food plays in Chinese culture, it is not surprising to see Chinese restaurant, food or dining scene become recognizably one of the most frequent scenes on screen. Anne Bower, in Reel food: essays on food and film, addresses the importance of food symbolism in films, "movie viewers respond so readily to food imagery because of food' primacy in our lives; it is a primacy that precedes literacy but then becomes part of our symbol-making, symbol-decoding capacity."17 Lee skillfully made use of food symbolism/ dining scene to subtly throw into the problems of intercultural communication between father and his daughter-in-law, as evidenced by four separate scenes, which will be explored in the following paragraphs.

The first conflict is effectively demonstrated by cooking scene, where Mr. Chu and Martha have their first face-to-face encounter in the kitchen. Chu's food is prepared and cooked in traditional Chinese ways, whereas Martha usually prepares herself a quick and simple lunch. As Lee explains, the setting is out of the consideration that both characters aim to "fight for their rights to the kitchen in a kind of territorial war." 18 This silent fight has already posed a challenge to Chu's concept of family defined by Confucian philosophers - family consciousness is constructed through a carefully built hierarchy which requires the family members to perform their fixed roles. The assumption by the father plays differently with Martha, who is driven by American individualism. Lee does not stop here; instead, he moves the conflict from the kitchen to the dining table. Once the cooking is done separately, Chu spontaneously sits down in front of Martha to join her for lunch. For him, sharing a meal at the same table symbolizes the construction of family. His good intention is not appreciated by Martha, though, since she has to fight to resist tempting food to keep her diet on track.

The second movie segment that sheds light on the conflict occurs at the dinner table, where three generations eat dinner together. Mr Chu and Martha, neither speaks the other's language, but both are eager to express their frustration to the third side - Alex, Chu's son and Martha's husband. This "fight for attention" scene can yet be interpreted as another territorial war, caused by lack of mutual understanding, on the basis of shared language and culture. Caught up in the middle, Alex is hesitant to take the role of translator during conversation. His intention of limiting the fight in fact amplifies the existing frustration. 
The conflict in the family intensifies at a faster, and the conflict reaches its peak in two fighting sequences, which feature Mr Chu playing taiji to defeat his opponents. The melodramatic effect is in general achieved through a dialectical relationship between pathos and action. ${ }^{19}$ Here pathos combines different types of emotions such as fear, anger, resentment, anxiety, sadness, and so on. Consequently, pathos will drive the characters to take action. It is, therefore, not surprising to see $\mathrm{Mr}$ Chu discharge emotions into action, leaving aside the question of whether the behavior is intentional or non-intentional.

Interestingly enough, both fighting scenes were shot in food-related location - one in cooking school and another in Chinese restaurant. When Mr. Chu starts to teach taiji to Chinese students in a training school at the Chinese community centre, he meets Mrs. Chen, who migrates from Taiwan to America and shares a similar feeling with Mr. Chu. Because of renovation, Mrs. Chen switches the teaching location to the classroom where Mr. Chu teaches Taiji. The camera captures the scene of a fat guy pushed ten meters away by Mr. Chu in the practice process and the well-made dumplings all thrown on the ground. I shall point out that the representation seemingly carries double implications. Careful audiences might have already sensed the attraction between two characters. On the one hand, it thus shows Mr. Chu's desire to impress Mrs. Chen by showing his masculine strength. The second interpretation is more related to the symbolic meaning of dumplings. Round dumplings in fact symbolize family reunion in Chinese traditional culture. By arranging this scene, Lee subtly throws into his doubt of "family reunion", which is answered by the final shot. Mr. Chu finally moves out of the house into Chinatown, and he leaves a note with bitter melodrama. The note says that rich life in America does not bring as much happiness to the family, as very few material things in China once did.

If the first fighting scene were more or less a practice, then the second one shows clearly how Lee creates the action for Mr. Chu as a means of breaking free from his repression. After leaving home, Chu ends up being a dishwasher in the Chinese restaurant. But he soon gets fired because of working too slowly. In confronting the owner of the restaurant, Chu is inevitably involved into the trouble. The hilarious fight is set in the kitchen of the Chinese restaurant.

The resolution for family-based melodramatic conflicts, for audiences who are familiar with Hollywood family melodrama, is usually achieved by castrating father, who fails his role as the authority figure. Lee however, provides a typical Chinese resolution for the family in Pushing Hands. Lee effectively applies the technique of pushing hands as a solution to the family problem, as the film title suggests. Similar to the utilization of melodrama in Chinese cinema that indicates mediation and negotiation across national and cultural borders, Pushing Hands also carries a symbolic meaning that suggests mediation between Chinese and American culture. Pushing hands, known as a type of internal Chinese martial arts, trains people to initiate positive contact with an opponent, rather than to immediately fight back or run away, when pushed by external forces, such as stress, problems or conflicts. The film thus serves to reflect the liberating spirit that in order to keep a balanced life in a new culture, the ability to respond positively to challenges plays an important role.

On several levels, the fictional father experiences being at home and not being at home at the same time. On the one hand, it is a family in a real sense, with three generations living under the same roof, which is supposed to enable family members to feel a strong sense of belonging. On the other hand, however, Chu's conventional definition of family violates Marsha's American way of thinking. The father in this film experiences twice uprooting. While the first time he willingly uproots himself from China to come to the United States for a joyful family reunion, the second time is more like a forced exile for the father. He chooses to leave home to minimize the irreconcilable conflicts within the family. A possible feminist's reading would interpret the father's second uprooting as a symbol of loss of power and authority, which is linked to castration. However, breaking up of the extended, and patriarchal family hierarchy in Pushing Hands can aid us in understanding Lee's reflection on 
the tension between tradition and modernity as well as his attempt to find a solution within the frame of traditional Chinese culture. Unity and harmony are equally important in traditional Chinese family values, but there are moments when one has to choose between two options. While employing the melodramatic form to offer a more accurate representation of the Chinese family, Lee is committed by his dual heritage - Chinese and American, which enables him to successfully transform "a Confucian tradition" into "a hybrid Confucian ethic and a spirit of capitalism".

\section{Conclusion}

So, with the complexity of diaspora experience central to his own identity, Ang Lee breaks up the boundary between realism and melodrama. This is particularly the case with postmodern dramatic forms, in which realism and melodrama, the highbrow culture and the popular culture, are often interwoven. In this way, Chinesecharacterized films become accessible to global audiences. Ang Lee's reinvention of melodramatic aesthetics, combining western generic conventions and Chinese characteristics, plays an important role in global cultural politics today, in which the flows of goods, people, and concepts are increasing, and the borders of cultures are more often than not emphasized but also blurred.

${ }^{1}$ Pushing Hands (1992) is the first feature film made by Chinese American filmmaker Ang Lee.

${ }^{2}$ Th. Elsaesser (1987), Tales of Sound and Fury, in Home Is Where The Heart Is, Christine Gledhill: British Film Institute, pp. 45.

3 Ibid., p. 1.

${ }^{4}$ The term "transnational Chinese cinema" used here is to encompass film-making activities that are located in various geographical regions but sharing cultural traits of "Chineseness".

${ }^{5}$ Th. Elsasser (1995), Tales of Sound and Fury, in B. K. Grant (Ed.): Film Genre Reader, Austin: University of Texas Press, p. 353.

${ }^{6}$ L. Williams (2002), Playing the race card: melodramas of Black and white from Uncle Tom to O.J. Simpson, Princeton University Press, p. 13.

7 P. Brooks (1976), The Melodramatic Imagination, Balzac, Henry James, and the Mode of Excess, New Haven: Yale University Press.

${ }^{8}$ I. Ang (1985), Watching Dallas: Soap Opera and the Melodramatic Imagination, Routledge, p. 64.

${ }^{9}$ Zheng Zhengqiu (郑正秋), Cai Chusheng (蔡楚生), and Xie Jin (谢晋 ) are recognizably famous filmmakers in Chinese movie history. More details in terms of substitutive modes can be found in $<<$ 西情节剧电影艺术比较研究 $>>$, 何春耕 (湖南大学出版社, 2008).

${ }^{10}$ Y. E. Yueh-yu (2009), Pitfalls of Cross-cultural Analysis: Chinese Wenyi Film and Melodrama. Asian Journal of Communication 19.4, pp. 438-452. 
${ }^{11}$ M. Ning (1993), Symbolic Representation and Symbolic Violence: Chinese Family Melodrama of the Early 1980s, in W. Dissanayake (Ed.), Melodrama and Asian Cinema, Cambridge University Press, p. 29.

12 Elsaesser (1987), p. 55.

13 Ibid., p. 58.

${ }^{14}$ E. A. Kaplan (2002), Women and Film, Routledge, p. 25.

15 Chr. Berry (2008), Rewriting Cinema: Markets, Languages, Cultures in Taiwan, in F.-L. Shih (Ed.), Re-writing culture in Taiwan, Rutledge, p. 148.

${ }^{16}$ B. Singer (2001), Melodrama and Modernity: Early Sensational Cinema and Its Contexts, Columbia University Press, p. 54.

${ }^{17}$ A. Bower (2004), Reel Food: Essays on Food and Film, Routledge, p. 10.

${ }^{18}$ Gourmet: Volume 55, Issues 1-6, P. V. Metzelthin (Ed.) (1995), Condé Nast Publications, p. 74.

${ }^{19}$ L. Williams, Melodrama Revised, in N. Brown (Ed.), Refiguring American Film Genres: Theory and History, Berkeley: University of California Press, p. 42.

Qijun Han completed her undergraduate studies with honors at Nanjing University with a major in English studies. She continued her study for Master Degree in American Studies at the School of Humanities at Utrecht University and finished her master thesis "The Evolution of Chinese Images in American Fiction Film" in 2009. In the same year, she started her PhD project at Utrecht University's Research Institute for History and Culture. She has worked intensively under the supervision of Prof. Frank Kessler, Prof. Rob Kroes, and Dr. Judith Keilbach on the topic of the cinematic representation of the Chinese family, particularly with an immigration background. She is a member of European American Studies network and of Utrecht University's MIRACLE Research Center for Moving Image Representations. 